\title{
The impact of vancomycin susceptibility on treatment outcomes among patients with methicillin resistant Staphylococcus aureus bacteremia
}

\author{
Hitoshi Honda ${ }^{1 * \dagger}$, Christopher D Doern ${ }^{2 \dagger}$, Wm Michael-Dunne $\mathrm{Jr}^{3+}$ and David K Warren ${ }^{1+}$
}

\begin{abstract}
Background: Management of methicillin-resistant Staphylococcus aureus (MRSA) bacteremia remains a challenge. The emergence of MRSA strains with reduced vancomycin susceptibility complicates treatment.

Methods: A prospective cohort study (2005-2007) of patients with MRSA bacteremia treated with vancomycin was performed at an academic hospital. Vancomycin minimum inhibitory concentration (MIC) and minimum bactericidal concentration (MBC) were determined for stored MRSA isolates. Cox regression analysis was performed to predict 28-day all-cause mortality.

Results: One hundred sixty-three patients with MRSA bacteremia were evaluated. One hundred twelve patients (68.7\%) had bacteremia due to MRSA with a vancomycin MIC $\geq 2 \mathrm{ug} / \mathrm{mL}$. Among strains with a vancomycin MIC $\geq$ $2 \mathrm{ug} / \mathrm{mL}, 10$ isolates (8.9\%) were vancomycin-intermediate S. aureus (VISA). Thirty-five patients (21.5\%) died within 28 days after the diagnosis of MRSA bacteremia. Higher vancomycin MIC was not associated with mortality in this cohort [adjusted hazard ratio (aHR), 1.57; 95\% confidence interval (Cl), 0.73-3.37]. Vancomycin tolerance was observed in 4.3\% (7/162) of isolates and was not associated with mortality (crude HR, 0.62; 95\% Cl, 0.08-4.50). Factors independently associated with mortality included higher age (aHR, 1.03; 95\% Cl 1.00-1.05), cirrhosis (aHR, 3.01; 95\% Cl, 1.24-7.30), and intensive care unit admission within 48 hours after the diagnosis of bacteremia (aHR, 5.99; $95 \% \mathrm{Cl}, 2.86-12.58)$.

Conclusions: Among patients with MRSA bacteremia treated with vancomycin, reduced vancomycin susceptibility and vancomycin tolerance were not associated with mortality after adjusting for patient factors. Patient factors including severity of illness and underlying co-morbidities were associated with the mortality.
\end{abstract}

\section{Background}

Methicillin-resistant Staphylococcus aureus (MRSA) bacteremia is a common infection. In a recent epidemiological study of nine US communities, the pooled mean incidence of MRSA bacteremia was 2.24 per 10, 000 population per year [1]. MRSA bacteremia is increasingly seen in the general community [2]. MRSA bacteremia is often complicated by medical device involvement, metastatic infection, recurrence, and mortality. MRSA

\footnotetext{
* Correspondence: hondah@hotmail.com

† Contributed equally

'Division of Infectious Diseases, Department of Medicine, Washington

University School of Medicine, St. Louis, Missouri, USA

Full list of author information is available at the end of the article
}

bacteremia is also associated with a worse outcome compared to bacteremia caused by methicillin-susceptible S. aureus [3-5]. Management of MRSA bacteremia is a challenge since clinical cure may not be achieved in selected cases, despite the appropriate antimicrobial therapy [6]. Vancomycin remains the mainstay treatment for MRSA bacteremia [7]. However, reduced vancomycin susceptibility may be associated with worse clinical outcomes (i.e., mortality or septic shock) among patients with MRSA bacteremia [8-10]. This observation led in part to the lowering of the breakpoint for vancomycin susceptibility to $\leq 2 \mu \mathrm{g} / \mathrm{mL}$ by the Clinical and Laboratory Standards Institute (CLSI) in 2006 [11].

\section{C) Biomed Central}


However, recent studies have demonstrated a variable association between vancomycin MIC and clinical outcome [12-14]. Some of this variability may be explained by other phenotypic characteristics such as vancomycin minimal bactericidal concentration $(\mathrm{MBC})$ or vancomycin tolerance $[15,16]$. The purpose of our study is to determine the impact of phenotypic characteristics on mortality of MRSA bacteremia using comprehensive data (2005-2007) from large prospective cohort at US tertiary hospital.

\section{Methods}

A prospective cohort study of patients with MRSA bacteremia was conducted between July 2005 and July 2007 at Barnes-Jewish Hospital, a 1252-bed, academic, tertiary care centre in St. Louis, Missouri. Diagnosis of MRSA bacteremia was defined as $\geq 1$ blood culture positive for MRSA. Patients who did not receive vancomycin as initial therapy or were less than 18 years old at the time of diagnosis of MRSA bacteremia were excluded. In order to analyze incident cases of invasive MRSA infections, patient who had a history of MRSA bacteremia in the previous three months, or a history of MRSA endocarditis in the twelve months prior to initial positive blood culture at our hospital during the study period were also excluded. Isolates from MRSA bacteremia were individually labeled and separately stored at $-40^{\circ}$ C for microbiological analysis.

\section{Microbiological analysis}

Minimum inhibitory concentrations (MIC) were determined by microbroth dilution method, using the SIEMENS (West Sacramento, CA) MicroScan ${ }^{\circledR}$ - Pos MIC Panel Type 26 as a testing platform. Briefly, MicroScan ${ }^{\circledR}$ panels were inoculated according to manufacturer's instruction using colonies of Staphylococcus aureus grown overnight on Remel tryptic soy agar blood agar plates (Lenexa, KS). Panels were incubated at $35^{\circ} \mathrm{C}$ in room air. Panels were run in full manual mode, and all microbroth dilution panels were manually read by a single investigator (C.D.C.) and MIC data was recorded for each isolate at 24 hours. The vancomycin doubling dilution range for this assay was from 0.25 to $16 \mathrm{mg} / \mathrm{L}$. Enterococcus faecalis ATCC 29212 and Staphylococcus aureus ATCC 29213 strains were used for quality control using the reference ranges provided in the package insert.

The MBC values were obtained using the method of Sader, et al. [17] The minimum bactericidal concentrations (MBC) for vancomycin were defined as $99.9 \%$ killing of the initial inocula after 24 hours of incubation. Following 24 hours of incubation, colony counts were conducted from the MIC well and every well thereafter demonstrating no bacterial growth. After thoroughly re- suspending each well, two aliquots of $20 \mu \mathrm{l}$ were plated to TSA blood agar plates for isolation and subsequent colony counts. An average of the two aliquots was multiplied by the dilution factor (1:5). The MBC was established as the first well with less than $99.9 \%$ of the initial inoculum. Repeat testing was conducted on those isolates with MBCs > $16 \mu \mathrm{g} / \mathrm{mL}$ to confirm the result. Vancomycin- intermediate $S$. aureus was defined as strains having a vancomycin MIC of 4 or $8 \mu \mathrm{g} / \mathrm{mL}$ by microbroth dilution testing [11]. Vancomycin tolerance was defined by either an MBC: $\mathrm{MIC}$ ratio $\geq 32$ or an $\mathrm{MBC}$ : MIC ratio of 16 associated with a resistant-level vancomycin MBC ( $\geq 32 \mu g / \mathrm{mL})$ [16-18].

\section{Definitions and data collection}

Patients were identified by daily review of microbiology reports. Demographic characteristics and clinical data were prospectively obtained from the medical record. A written informed consent from the patients was waived for this observational study. We tracked all-cause mortality for 28 days after the first blood culture positive for MRSA by reviewing both medical records and the Social Security Death Index [19]. If the patient did not die on initial hospital stay, then any patients readmitted $>28$ days after the initial diagnosis of MRSA bacteremia were considered to be alive at 28 days. If there were no readmission data $>28$ days after diagnosis of MRSA bacteremia available, Social Security Death Index was used to determine if patients died. Metastatic infection was defined by microbiological or radiographic evidence of remote site of infection consistent with hematogenous spread [20]. Healthcare-associated, hospital-onset bacteremia was defined by a positive blood culture obtained from patients who were hospitalized $>48$ hours [21]. Healthcare-associated, community onset of bacteremia was defined as a positive blood culture $\leq 48$ hours after hospitalization with the following criteria; presence of an invasive device, history of MRSA infection or colonization, surgery, hospitalization, dialysis, or residence in a long-term care facility in the 12 months preceding the culture [21]. Community-associated bacteremia was defined by a positive blood culture $\leq 48$ hours without meeting the criteria of healthcare associated community-onset bacteremia [21].

\section{Statistical analyses}

Vancomycin MIC was dichotomized (MIC of $\leq 1 \mu \mathrm{g} / \mathrm{mL}$ and $\mathrm{MIC} \geq 2 \mu \mathrm{g} / \mathrm{mL}$ ). Comparison between categorical variables was done using Chi-square or Fisher's exact test. Continuous variables were compared using the Mann-Whitney test. Two-tailed Spearman's rho was used to calculate correlation coefficients between vancomycin MIC and MBC. All tests for significance were 2tailed, with $P$ values $<0.05$ considered significant. 
We performed multivariable survival analysis to predict 28-day all-cause mortality. Potential risk factors for 28-day all-cause mortality were first assessed by bivariate analysis. A Cox proportional hazards model was developed in forward stepwise fashion to predict mortality. The variable of vancomycin MIC (either $\leq 1 \mu \mathrm{g} / \mathrm{mL}$ or $\geq 2 \mu g / \mathrm{mL}$ ) was forced into the final model since this was the independent variable of interest. Variables with $P<0.10$ in bivariate analysis were considered for inclusion in the models. The assumption of proportional hazards was confirmed by log-log survival plots for independent variables in the final model. A first-order interaction term of initial vancomycin trough level $(<$ or $\geq$ $15 \mu \mathrm{g} / \mathrm{dL}$ ) and vancomycin MIC was created to determine if a lower vancomycin trough and higher vancomycin MIC independently increased mortality. Other variables were retained in the final model if $P<0.05$. All analyses were performed using SPSS version 17.0 (SPSS Inc, Chicago, IL). The Washington University Human Research Protection (institutional review board) approved this project.

\section{Results}

One hundred-sixty three patients met study criteria during the 25-month study period and were included in the analysis. The vancomycin MIC was $\leq 1 \mu \mathrm{g} / \mathrm{mL}$ for 51 (31.3\%) isolates, and $\geq 2 \mu \mathrm{g} / \mathrm{mL}$ for $112(68.7 \%)$ isolates $\left(\mathrm{MIC}_{50}=2 \mu \mathrm{g} / \mathrm{mL}\right)$. Ten isolates $(6.1 \%)$ had a vancomycin $\mathrm{MIC}$ of $4 \mu \mathrm{g} / \mathrm{mL}$. Only one isolate had a vancomycin MIC of $0.5 \mu g / \mathrm{mL}$. There were no isolates with a vancomycin $\mathrm{MIC}>4 \mu \mathrm{g} / \mathrm{mL}$ in this cohort.

The vancomycin $\mathrm{MBC}$ for all isolates ranged from 1 to $\geq 32 \mu \mathrm{g} / \mathrm{mL}\left(\mathrm{MBC}_{50}\right.$ and $\mathrm{MBC}_{90}$ were $2 \mu \mathrm{g} / \mathrm{mL}$ and 8 $\mu g / \mathrm{mL}$, respectively, Table 1$)$. Seven (4.3\%) isolates met the criteria for vancomycin tolerance, while the MBC: $\mathrm{MIC}$ ratio to determine vancomycin tolerance for one isolate could not be determined (The strain with a vancomycin MIC of $4 \mu \mathrm{g} / \mathrm{mL}$ and $\mathrm{MBC} \geq 32 \mu \mathrm{g} / \mathrm{mL})$.

\begin{tabular}{|c|c|c|c|c|c|c|c|}
\hline \multirow[b]{2}{*}{$\begin{array}{c}\text { Vancomycin } \\
\text { MIC } \\
\text { (ug/mL) }\end{array}$} & \multirow[b]{2}{*}{$\begin{array}{c}\text { No. of isolates } \\
\text { (\%) } \\
(n=163)\end{array}$} & \multicolumn{6}{|c|}{ Vancomycin MBC (ug/mL) } \\
\hline & & 1 & 2 & 4 & 8 & 16 & $\geq 32$ \\
\hline$<1$ & $1(0.6)$ & - - & 1 & - & - & - - & - \\
\hline 1 & $50(30.6)$ & 37 & 12 & - & - & 1 & 一一 \\
\hline 2 & $102(62.6)$ & - - & 75 & 14 & 6 & - - & $7^{\mathrm{a}}$ \\
\hline 4 & $10(6.1)$ & - - & - & 7 & 1 & 1 & $1^{\mathrm{b}}$ \\
\hline
\end{tabular}

MIC, minimum inhibitory concentration; MBC, minimum bactericidal concentration.

a. Seven isolates were met the criteria for vancomycin tolerance.

b. MBC: MIC ratio for one isolate was undetermined.
Overall, vancomycin MIC was highly correlated with vancomycin $\mathrm{MBC}(\mathrm{r}=0.734, \mathrm{p}<0.001)$. A comparison of study patients by vancomycin MIC is shown in Table 2. There were no significant differences in patient characteristics between patients infected with MRSA isolates having low versus high vancomycin MICs.

The 28-day all-cause mortality rate for the cohort was $21.5 \%$. Median length of time from the time of first positive blood culture to death was 13 days (range; 1-28 days). Predictors of 28-day mortality of MRSA bacteremia are shown in Table 3. Increased age, chronic renal insufficiency without dialysis, cirrhosis, vascular graft, central venous catheter at the time of bacteremia, ICU admission within 48 hours at the time of first positive blood culture, and vancomycin MIC > $2 \mu \mathrm{g} / \mathrm{mL}$ were considered for inclusion in the multivariate model. In the multivariate model, factors independently associated with mortality were increased age [adjusted hazard ratio (aHR), 1.03 per year; 95\% confidence interval (CI), 1.001.05], cirrhosis (aHR, 3.01; 95\% CI, 1.24-7.30), and ICU admission within 48 hours of diagnosis (aHR, 5.99; 95\% CI, 2.86-12.58). Lower initial vancomycin trough level (i. e., $<15 \mu \mathrm{g} / \mathrm{dL}$ ) was not associated with 28-day mortality ( $n=151$, crude HR, 0.77; 95\% CI, 0.36-1.63). MRSA phenotype characteristics, both vancomycin susceptibility $\geq 2 \mu \mathrm{g} / \mathrm{mL}$ (adjusted HR, 1.57; 95\% CI, 0.73-3.37) and vancomycin tolerance $(\mathrm{n}=162$, crude $\mathrm{HR}, 0.62$; $95 \%$ CI, 0.08-4.50) were not associated with 28-day mortality.

\section{Discussion}

In contrast to previous studies, [8-10] we did not observe an association between 28-day all-cause mortality and increased vancomycin MIC ( $\geq 2 \mu \mathrm{g} / \mathrm{ml}$ ) or vancomycin tolerance among patients with MRSA bacteremia, after adjusting for underlying patient factors.

In this prospective cohort, the incidence of MRSA bacteremia due to strains with a vancomycin MIC of 2 $\mu g / \mathrm{ml}$ and VISA bacteremia (i.e., MIC ranging 4-8 $\mu g /$ $\mathrm{ml}$ ) was $62.6 \%$ and $6.1 \%$, respectively. According to 2005 Surveillance Network data from a large sample of US laboratories, S. aureus isolates with reduced susceptibility to vancomycin was rare; the percentage of over 240, 000 isolates with vancomycin MIC of $2 \mu \mathrm{g} / \mathrm{ml}$ and vancomycin MIC $\geq 4$ was $16.2 \%$ and $0.2 \%$, respectively [11]. Musta et al. showed in their cohort, the percentage of MRSA blood culture isolates with a vancomycin MIC of $2 \mu \mathrm{g} / \mathrm{ml}$ (including $1.5 \mu \mathrm{g} / \mathrm{ml}$ ) and > $2 \mu \mathrm{g} / \mathrm{ml}$ was $82.8 \%$ and $2.7 \%$, respectively [13]. The reason for our cohort having a higher prevalence of strains with reduced vancomycin susceptibility and VISA was not completely clear. The current prevalence of VISA in the US is unknown. Since our cohort included the data from 2007 , this might be indicative of an overall increase in 
Table 2 Comparison of 163 Patients with Methicillin-Resistant Staphylococcus aureus Bacteremia, by Vancomycin Minimum Inhibitory Concentration

\begin{tabular}{|c|c|c|c|}
\hline \multirow[t]{2}{*}{ Variable } & \multicolumn{2}{|c|}{ MIC (ug/mL) } & \multirow[b]{2}{*}{$p$} \\
\hline & $\begin{array}{c}\leq 1 \\
(n=51)\end{array}$ & $\begin{aligned} & \geq 2 \\
(n & =112)\end{aligned}$ & \\
\hline Age, years, median (range) & $54(26-95)$ & $59(23-92)$ & .115 \\
\hline Female gender & $23(45.1)$ & $60(53.6)$ & .316 \\
\hline White race & $22(43.1)$ & $51(45.5)$ & .775 \\
\hline Congestive heart failure & $10(19.6)$ & $25(22.3)$ & .696 \\
\hline Coronary artery disease & $11(21.6)$ & $26(23.2)$ & .817 \\
\hline Chronic obstructive pulmonary diseases & $15(29.4)$ & $22(19.6)$ & .167 \\
\hline \multicolumn{4}{|l|}{ Renal function } \\
\hline Normal & $36(70.6)$ & $81(72.3)$ & Ref. $^{c}$ \\
\hline Chronic renal insufficiency without dialysis & $4(7.8)$ & $10(8.9)$ & .866 \\
\hline Chronic renal insufficiency with dialysis & $11(21.6)$ & $21(18.8)$ & .697 \\
\hline Malignancy & $10(19.6)$ & $25(22.3)$ & .696 \\
\hline HIV infection & $4(7.8)$ & $3(2.7)$ & .206 \\
\hline Chronic skin disease & $5(9.8)$ & $8(7.1)$ & .547 \\
\hline Peripheral vascular diseases & $4(7.8)$ & $7(6.3)$ & .741 \\
\hline Diabetes mellitus & $27(52.9)$ & $34(30.4)$ & .006 \\
\hline Systemic corticosteroid use last 28 days & $9(17.6)$ & $15(13.4)$ & .477 \\
\hline Cirrhosis & $4(7.8)$ & $10(8.9)$ & 1.00 \\
\hline History of intravenous drug use & $4(7.8)$ & $11(9.8)$ & .778 \\
\hline History of smoking & $29(56.9)$ & $67(58.9)$ & .865 \\
\hline Any transplant & $2(3.9)$ & $8(7.1)$ & .726 \\
\hline Surgery during hospitalization & $10(19.6)$ & $13(11.6)$ & .174 \\
\hline Prosthetic joint & $4(7.8)$ & $11(9.8)$ & .778 \\
\hline Vascular graft & $9(17.6)$ & $14(12.5)$ & .381 \\
\hline Cardiac device & $4(7.8)$ & $6(5.4)$ & .506 \\
\hline ICU admission within 48 hours after the first positive blood culture & $19(37.3)$ & $40(35.7)$ & .849 \\
\hline Central venous catheterization at the time of the first $(+)$ blood culture & $37(72.5)$ & $77(68.8)$ & .624 \\
\hline \multicolumn{4}{|l|}{ Onset } \\
\hline Community-associated & $4(7.8)$ & $8(7.1)$ & Ref. $^{c}$ \\
\hline Healthcare-associated community onset & $32(62.7)$ & $66(58.9)$ & .962 \\
\hline Healthcare-associated hospital onset & $15(29.4)$ & $38(33.9)$ & .730 \\
\hline \multicolumn{4}{|l|}{ Site of MRSA bacteremia } \\
\hline Primary bacteremia & $25(49.0)$ & $45(40.2)$ & $\operatorname{Ref}^{c}$ \\
\hline Catheter related bloodstream infection & $12(23.5)$ & $25(22.3)$ & .344 \\
\hline Skin infection & $8(15.7)$ & $17(15.2)$ & .508 \\
\hline Postoperative surgical site infection & $2(3.9)$ & $12(10.7)$ & .552 \\
\hline Other & $4(7.8)$ & $13(11.6)$ & .520 \\
\hline Any metastatic infection at the time of diagnosis & $6(11.8)$ & $17(15.2)$ & .562 \\
\hline \multicolumn{4}{|l|}{ Outcome } \\
\hline Recurrent MRSA infection $(n=161)^{a, b}$ & 10/51 (19.6) & $16 / 110(14.5)$ & .417 \\
\hline Death at 28 days after diagnosis of bacteremia & $9(17.6)$ & $26(23.2)$ & .422 \\
\hline
\end{tabular}

HIV, human immunodeficiency virus; ICU, intensive care unit; MRSA, methicillin-resistant S. aureus. Ref, reference; MIC, minimum inhibitory concentration.

a. See methods for definition.

b. Two patients were excluded from analysis since they died within 48 hours of diagnosis. c. $P$ value determined using univariate logistic regression.

Percentage of each column with variable is shown in parentheses, unless otherwise stated. 
Table 3 Predictors of 28-day All-Cause Mortality after Diagnosis of Methicillin-Resistant Staphylococcus aureus Bacteremia for 163 Patients

\begin{tabular}{|c|c|c|c|c|}
\hline Variable & $\begin{array}{l}\text { Death } \\
(\mathrm{n}=35)\end{array}$ & $\begin{array}{c}\text { Alive } \\
(n=128)\end{array}$ & $\begin{array}{l}\text { Crude HR } \\
(95 \% \mathrm{Cl})\end{array}$ & $\begin{array}{l}\text { Adjusted HR } \\
(95 \% \mathrm{Cl})\end{array}$ \\
\hline Age, years, median (range) & $64(33-92)$ & $56(23-95)$ & $1.03(1.00-1.05)$ & $1.03(1.00-1.05)$ \\
\hline Female gender & $16(45.7)$ & $67(52.3)$ & $0.83(0.43-1.61)$ & \\
\hline White race & $20(57.1)$ & $70(54.7)$ & $1.05(0.54-2.05)$ & \\
\hline Congestive heart failure & $9(25.7)$ & $26(20.3)$ & $1.33(0.62-2.84)$ & \\
\hline Coronary artery disease & $8(22.9)$ & $29(22.7)$ & $0.99(0.45-2.19)$ & \\
\hline Chronic obstructive pulmonary diseases & $10(28.6)$ & $27(21.1)$ & $1.43(0.69-2.97)$ & \\
\hline \multicolumn{5}{|l|}{ Renal function } \\
\hline Normal & $25(71.4)$ & $92(71.9)$ & Reference & \\
\hline CRI without dialysis & $7(20.0)$ & $7(5.5)$ & $2.67(1.15-6.17)$ & \\
\hline CRI with dialysis & $3(8.6)$ & $29(22.7)$ & $0.42(0.13-1.37)$ & \\
\hline Malignancy & $8(22.9)$ & $27(21.1)$ & $1.08(0.49-2.37)$ & \\
\hline HIV infection & $1(2.9)$ & $6(4.7)$ & $0.58(0.08-4.26)$ & \\
\hline Chronic skin disease & $2(5.7)$ & $11(8.6)$ & $0.69(0.17-2.87)$ & \\
\hline Peripheral vascular diseases & $2(5.7)$ & $9(7.0)$ & $0.81(0.19-3.37)$ & \\
\hline Diabetes mellitus & $10(28.6)$ & $51(39.8)$ & $0.64(0.31-1.32)$ & \\
\hline Systemic corticosteroid use last 28 days & $8(22.9)$ & $16(12.5)$ & $2.01(0.91-4.42)$ & \\
\hline Cirrhosis & $6(17.1)$ & $8(6.3)$ & $2.50(1.04-6.02)$ & $3.01(1.24-7.30)$ \\
\hline History of intravenous drug use & $2(5.7)$ & $13(10.2)$ & $0.57(0.14-2.37)$ & \\
\hline History of smoking & $22(62.9)$ & $73(57.0)$ & $1.27(0.64-2.52)$ & \\
\hline Alcohol use & $11(31.4)$ & $39(30.5)$ & $1.06(0.52-2.15)$ & \\
\hline Any transplant & $2(5.7)$ & $8(6.3)$ & $0.89(0.22-3.73)$ & \\
\hline Surgery during hospitalization & $4(11.4)$ & $19(14.8)$ & $0.78(0.28-2.21)$ & \\
\hline Prosthetic joint & 0 & $15(11.7)$ & $0.04(0-5.06)$ & \\
\hline Vascular graft & $1(2.9)$ & $22(17.2)$ & $0.16(0.02-1.16)$ & \\
\hline Cardiac device & $3(8.6)$ & $7(5.5)$ & $1.40(0.43-4.56)$ & \\
\hline ICU admission within 48 hours after the first positive blood culture & $25(71.4)$ & $34(26.6)$ & $5.56(2.67-11.60)$ & $5.99(2.86-12.58)$ \\
\hline Central venous catheterization at the time of the first positive blood culture & $29(82.9)$ & $85(66.4)$ & $2.25(0.93-5.42)$ & \\
\hline \multicolumn{5}{|l|}{ Onset } \\
\hline Community-associated & $3(8.6)$ & $9(7.0)$ & Reference & \\
\hline Healthcare-associated community onset & $21(60.0)$ & $77(60.2)$ & $0.76(0.23-2.55)$ & \\
\hline Healthcare-associated hospital onset & $11(31.4)$ & $42(32.8)$ & $0.75(0.21-2.67)$ & \\
\hline Any metastatic infection at the time of diagnosis & $6(17.1)$ & $17(13.3)$ & $1.27(0.53-3.05)$ & \\
\hline Vancomycin tolerance $(n=162)^{a, b}$ & $1 / 35(2.9)$ & $6 / 127(4.7)$ & $0.62(0.08-4.50)$ & \\
\hline $\begin{array}{l}\text { Vancomycin initial trough }<15 \mathrm{mg} / \mathrm{L} \\
(\mathrm{n}=151)^{c}\end{array}$ & 14/27 (51.9) & 73/124 (58.9) & $0.77(0.36-1.63)$ & \\
\hline Vancomycin MIC $\geq 2 \mathrm{ug} / \mathrm{mL}$ & $26(74.3)$ & $86(67.2)$ & $1.36(0.64-2.89)$ & $1.57(0.73-3.37)$ \\
\hline
\end{tabular}

CRI, chronic renal insufficiency; HIV, human immunodeficiency virus; ICU, intensive care unit; MRSA, methicillin-resistant S. aureus; HR, hazard ratio; MIC, minimum inhibitory concentration.

Variables considered but not retained in the final model were renal function (chronic renal failure without dialysis), vascular graft, central venous catheterization at the time of diagnosis, and vancomycin MIC $\geq 2 \mathrm{ug} / \mathrm{mL}$.

a. See methods for definition.

b. One patient was excluded since MBC: MIC ratio was undetermined.

c. Twelve patients did not have an initial vancomycin trough level. [unknown reason $(n=7)$ or died before initial trough was obtained $(n=5)$ ]

vancomycin MIC among MRSA. However, a large sample of isolates must be tested to confirm this.

In previous studies, Soriano et al, demonstrated progressively higher vancomycin MICs (ranging between 1, 1.5 , and $2 \mu \mathrm{g} / \mathrm{ml}$ ) were associated with increased 30-day mortality when vancomycin was used to treat MRSA bacteremia [10]. A paradoxical relationship (i.e., increased vancomycin MIC was correlated with better clinical outcome) was also observed in one study [14]. The discordant finding of these various studies has generated several hypotheses, including a potential difference in strain virulence due to geographic location. Although a trend towards increased mortality was observed among our few patients infected with MRSA 
isolates with vancomycin MIC of $4 \mu \mathrm{g} / \mathrm{ml}$, this was not statistically significant (data not shown).

Among the 151 patients in which an initial vancomycin trough was obtained, a lower vancomycin trough level was not associated with increased mortality in our cohort, which has been reported by others [22]. Treatment failure of MRSA bacteremia using vancomycin raises questions about the ideal serum vancomycin concentration for treatment of $S$. aureus bacteremia. Based on limited animal studies and Monte Carlo simulation studies, the targeted therapeutic range of vancomycin [area under the concentration-versus-time curve (AUC): MIC of $\geq 400$ ] is not achievable with conventional vancomycin dosing if the MIC is $\geq 2 \mu \mathrm{g} / \mathrm{ml}$ in patients with normal renal function [23,24]. This led to a recommendation not to use vancomycin for a AUC:MIC ratio $\geq$ 400. However, there is no definitive human clinical data to support this recommendation [24]. Moreover, nephrotoxicity is a concern when a higher dose of vancomycin is administered [25]. We created a model with an interaction variable for both higher vancomycin $(\geq 2$ $\mu g / \mathrm{ml})$ and lower initial vancomycin trough level $(<15$ $\mathrm{mg} / \mathrm{L}$ ), however this interaction variable was not associated with increased mortality (data not shown). Our finding supports the hypothesis that vancomycin MIC of $2 \mu \mathrm{g} / \mathrm{ml}$ may not always predict worse outcome in patients with MRSA bacteremia.

The effect of vancomycin MBC and vancomycin tolerance on patient outcome have rarely been examined in clinical practice. Vancomycin tolerance may be associated with reduced efficacy of antimicrobials (i.e., bactericidal or bacteriostatic activity) based on animal models [26]. In our cohort, the incidence of vancomycin tolerance was approximately $4 \%$. We did not observe an association between vancomycin tolerance and increased mortality although we had small numbers of vancomycin-tolerant isolates in our cohort. In our study, vancomycin MBC was highly correlated with vancomycin MIC; over $70 \%$ of isolates revealed an identical value of vancomycin MIC and MBC. Based on our findings, $\mathrm{MBC}$ and vancomycin tolerance is likely to be of limited value as a predictor of outcomes in MRSA bacteremia patients treated with vancomycin.

Our study demonstrated that patient factors, such as patient's age, co-morbidities, presence of devices, and ICU admission $\leq 48$ hours after first positive blood culture are predictive of short-term mortality associated with MRSA bacteremia, similar to what has been noted by others [27-29]. This suggests that earlier identification of high risk patients, and timely management in the early stage of illness are important in reducing mortality in MRSA bacteremia.

Our study has several limitations. It occurred in a single, tertiary care center, and may not be generalizable to other hospitals. The extent of diseases associated with MRSA bacteremia was not fully evaluated in this study, especially the presence of endocarditis, since not all patients with MRSA bacteremia underwent further evaluation such as transesophageal echocardiogram [30]. In this cohort, transesophageal echocardiogram was only performed for only $17.2 \%$ (18/163) of patients. Clinical information at the time of diagnosis, such as, intensive care unit admission 48 hours or less at the time of diagnosis, active malignancy, and cirrhosis was used as a predictor of the severity of the illness. We were unable to collect information to calculate Acute Physiology and Chronic Health Evaluation II score and Charlson comorbidity index which may be more appropriate for a predictor of the severity of illness. Although vancomycin trough level was are generally obtained before the fourth dose at our institution, $7.4 \%$ of patients in our study did not have a trough level drawn, and the timing of when vancomycin trough level were obtained for the remainder of other cohort was not standardized. Persistent bacteremia (i.e., $>7$ days bacteremia) [31] occurred in only one patient in our cohort; therefore, we were unable to assess the relationship between vancomycin MIC and duration of bacteremia. Despite having prospective data on over 163 patients and an overall mortality rate of $21.5 \%$, our study is not powered to detect small differences in mortality due to infection from MRSA isolates with either low or high vancomycin MICs. While our data did not support a direct relationship vancomycin MIC and mortality in patients with MRSA bacteremia, this finding may not apply to other invasive MRSA infection, especially those involving other organs (e.g., central nervous system, bone, and eye) in which the physiologically achievable vancomycin concentration is lower than in blood. Due to the low incidence of VISA bacteremia in our cohort, we were unable to assess the impact of VISA on mortality.

\section{Conclusion}

We found that reduced vancomycin susceptibility and vancomycin tolerance were not associated with significant differences in 28-day mortality among a cohort of patients with MRSA bacteremia. Other patient risk factors are likely associated with unfavorable clinical outcome. Even with the rising incidence of infections due to MRSA strains with reduced vancomycin MIC, vancomycin is still the first-line agent for treating MRSA bacteremia. Our data suggest that for bacteremia due to MRSA with a vancomycin MIC of $2 \mu \mathrm{g} / \mathrm{mL}$, vancomycin may still remain a viable treatment option.

\section{Acknowledgements}

The manuscript was presented at $48^{\text {th }}$ annual meeting of the Infectious Diseases Society of America (2010). 
Financial support

CDC EpiCenter (5-U01-Cl0000333-05), BJH Foundation (6826-02 \& 6826-01), Cubist Pharmaceuticals.

\section{Author details}

'Division of Infectious Diseases, Department of Medicine, Washington University School of Medicine, St. Louis, Missouri, USA. ${ }^{2}$ Department of Pathology, University of Texas Southwestern Medical Center, Dallas, Texas, USA. ${ }^{3}$ Department of Pathology and Immunology, Washington University School of Medicine, St. Louis, Missouri, USA.

\section{Authors' contributions}

$\mathrm{HH}$ collected the clinical information of cohort data and participated in the design of the study, performed statistical analysis, and prepared manuscript. CDD performed phenotypic testing of isolates.

WMD participated in the design of the study and performed phenotypic testing of isolates.

DKW conceived of the study, and participated in its design and coordination and helped to draft the manuscript. All authors read and approved the final manuscript.

\section{Competing interests}

DKW reports that he is a consultant for $3 \mathrm{M}$ Healthcare and Cardinal Health and receives research funding from Sage Products, 3M Healthcare, bioMeriéux, and Cubist Pharmaceuticals

All other authors report no conflicts of interest relevant to this article.

Received: 29 July 2011 Accepted: 5 December 2011

Published: 5 December 2011

\section{References}

1. Kallen AJ, Mu Y, Bulens S, Reingold A, Petit S, Gershman K, Ray SM, Harrison LH, Lynfield R, Dumyati G, Townes JM, Schaffner W, Patel PR, Fridkin SK: Health care-associated invasive MRSA infections, 2005-2008. JAMA 2010, 304(6):641-8.

2. Community-associated methicillin-resistant Staphylococcus aureus infection among healthy newborns-Chicago and Los Angeles County, 2004. MMWR Morb Mortal Wkly Rep 2006, 55(12):329-32.

3. Conterno LO, Wey SB, Castelo A: Risk factors for mortality in Staphylococcus aureus bacteremia. Infect Control Hosp Epidemiol 1998, 19(1):32-7.

4. Cosgrove SE, Sakoulas G, Perencevich EN, Schwaber MJ, Karchmer AW Carmeli Y: Comparison of mortality associated with methicillin-resistant and methicillin-susceptible Staphylococcus aureus bacteremia: a metaanalysis. Clin Infect Dis 2003, 36(1):53-9.

5. Romero-Vivas J, Rubio M, Fernandez C, Picazo JJ: Mortality associated with nosocomial bacteremia due to methicillin-resistant Staphylococcus aureus. Clin Infect Dis 1995, 21(6):1417-23.

6. Hawkins C, Huang J, Jin N, Noskin GA, Zembower TR, Bolon M: Persistent Staphylococcus aureus bacteremia: an analysis of risk factors and outcomes. Arch Intern Med 2007, 167(17):1861-7.

7. Moellering RC Jr: Vancomycin: a 50-year reassessment. Clin Infect Dis 2006, 42(Suppl 1):S3-4.

8. Howden BP, Ward PB, Charles PG, Korman TM, Fuller A, du Cros P, Grabsch EA, Roberts SA, Robson J, Read K, Bak N, Hurley J, Johnson PD, Morris AJ, Mayall BC, Grayson ML: Treatment outcomes for serious infections caused by methicillin-resistant Staphylococcus aureus with reduced vancomycin susceptibility. Clin Infect Dis 2004, 38(4):521-8.

9. Lodise TP, Graves J, Evans A, Graffunder E, Helmecke M, Lomaestro BM, Stellrecht K: Relationship between vancomycin MIC and failure among patients with methicillin-resistant Staphylococcus aureus bacteremia treated with vancomycin. Antimicrob Agents Chemother 2008, 52(9):3315-20.

10. Soriano A, Marco F, Martinez JA, Pisos E, Almela M, Dimova VP, Alamo D, Ortega M, Lopez J, Mensa J: Influence of vancomycin minimum inhibitory concentration on the treatment of methicillin-resistant Staphylococcus aureus bacteremia. Clin Infect Dis 2008, 46(2):193-200.

11. Tenover FC, Moellering RC Jr: The rationale for revising the Clinical and Laboratory Standards Institute vancomycin minimal inhibitory concentration interpretive criteria for Staphylococcus aureus. Clin Infect Dis 2007, 44(9):1208-15.
12. Lalueza A, Chaves F, San Juan R, Daskalaki M, Otero JR, Aguado JM: Is high vancomycin minimum inhibitory concentration a good marker to predict the outcome of methicillin-resistant Staphylococcus aureus bacteremia? J Infect Dis 2010, 2: 311-2, author reply 2-3.

13. Musta AC, Riederer K, Shemes S, Chase P, Jose J, Johnson LB, Khatib R: Vancomycin MIC plus heteroresistance and outcome of methicillinresistant Staphylococcus aureus bacteremia: trends over 11 years. J Clin Microbiol 2009, 47(6):1640-4.

14. Price J, Atkinson S, Llewelyn M, Paul J: Paradoxical relationship between the clinical outcome of Staphylococcus aureus bacteremia and the minimum inhibitory concentration of vancomycin. Clin Infect Dis 2009, 48(7):997-8.

15. French GL: Bactericidal agents in the treatment of MRSA infections-the potential role of daptomycin. J Antimicrob Chemother 2006, 58(6):1107-17.

16. Jones RN: Microbiological features of vancomycin in the 21 st century: minimum inhibitory concentration creep, bactericidal/static activity, and applied breakpoints to predict clinical outcomes or detect resistant strains. Clin Infect Dis 2006, 42(Suppl 1):S13-24.

17. Sader HS, Fritsche TR, Jones RN: Daptomycin bactericidal activity and correlation between disk and broth microdilution method results in testing of Staphylococcus aureus strains with decreased susceptibility to vancomycin. Antimicrob Agents Chemother 2006, 50(7):2330-6.

18. May J, Shannon K, King A, French G: Glycopeptide tolerance in Staphylococcus aureus. J Antimicrob Chemother 1998, 42(2):189-97.

19. Quinn J, Kramer N, McDermott D: Validation of the Social Security Death Index (SSDI): An Important Readily-Available Outcomes Database for Researchers. West J Emerg Med 2008, 9(1):6-8.

20. Jenkins TC, Price CS, Sabel AL, Mehler PS, Burman WJ: Impact of routine infectious diseases service consultation on the evaluation, management, and outcomes of Staphylococcus aureus bacteremia. Clin Infect Dis 2008, 46(7):1000-8.

21. Klevens RM, Morrison MA, Fridkin SK, Reingold A, Petit S, Gershman K, Ray S, Harrison LH, Lynfield R, Dumyati G, Townes JM, Craig AS, Fosheim G, McDougal LK, Tenover FC: Community-associated methicillin-resistant Staphylococcus aureus and healthcare risk factors. Emerg Infect Dis 2006, 12(12):1991-3.

22. Jeffres MN, Isakow W, Doherty JA, McKinnon PS, Ritchie DJ, Micek ST, Kollef MH: Predictors of mortality for methicillin-resistant Staphylococcus aureus health-care-associated pneumonia: specific evaluation of vancomycin pharmacokinetic indices. Chest 2006, 130(4):947-55.

23. Moise-Broder PA, Sakoulas G, Eliopoulos GM, Schentag JJ, Forrest A, Moellering RC Jr: Accessory gene regulator group II polymorphism in methicillin-resistant Staphylococcus aureus is predictive of failure of vancomycin therapy. Clin Infect Dis 2004, 38(12):1700-5.

24. Rybak M, Lomaestro B, Rotschafer JC, Moellering R Jr, Craig W, Billeter M, Dalovisio JR, Levine DP: Therapeutic monitoring of vancomycin in adult patients: a consensus review of the American Society of Health-System Pharmacists, the Infectious Diseases Society of America, and the Society of Infectious Diseases Pharmacists. Am J Health Syst Pharm 2009, 66(1):82-98.

25. Lodise TP, Patel N, Lomaestro BM, Rodvold KA, Drusano GL: Relationship between initial vancomycin concentration-time profile and nephrotoxicity among hospitalized patients. Clin Infect Dis 2009, 49(4):507-14.

26. Tuomanen E, Durack DT, Tomasz A: Antibiotic tolerance among clinical isolates of bacteria. Antimicrob Agents Chemother 1986, 30(4):521-7.

27. Kim SH, Park WB, Lee KD, Kang Cl, Kim HB, Oh MD, Kim EC, Choe KW: Outcome of Staphylococcus aureus bacteremia in patients with eradicable foci versus noneradicable foci. Clin Infect Dis 2003, 37(6):794-9.

28. McClelland RS, Fowler VG Jr, Sanders LL, Gottlieb G, Kong LK, Sexton DJ, Schmader K, Lanclos KD, Corey R: Staphylococcus aureus bacteremia among elderly vs younger adult patients: comparison of clinical features and mortality. Arch Intern Med 1999, 159(11):1244-7.

29. Mylotte JM, Tayara A: Staphylococcus aureus bacteremia: predictors of 30-day mortality in a large cohort. Clin Infect Dis 2000, 31(5):1170-4.

30. Fowler VG Jr, Li J, Corey GR, Boley J, Marr KA, Gopal AK, Kong LK, Gottlieb G, Donovan CL, Sexton DJ, Ryan T: Role of echocardiography in evaluation of patients with Staphylococcus aureus bacteremia: experience in 103 patients. J Am Coll Cardiol 1997, 30(4):1072-8.

31. Fowler VG Jr, Sakoulas G, Mclntyre LM, Meka VG, Arbeit RD, Cabell CH Stryjewski ME, Eliopoulos GM, Reller LB, Corey GR, Jones T, Lucindo N, 
Yeaman MR, Bayer AS: Persistent bacteremia due to methicillin-resistant Staphylococcus aureus infection is associated with agr dysfunction and low-level in vitro resistance to thrombin-induced platelet microbicidal protein. J Infect Dis 2004, 190(6):1140-9.

Pre-publication history

The pre-publication history for this paper can be accessed here: http://www.biomedcentral.com/1471-2334/11/335/prepub

doi:10.1186/1471-2334-11-335

Cite this article as: Honda et al:: The impact of vancomycin susceptibility on treatment outcomes among patients with methicillin resistant Staphylococcus aureus bacteremia. BMC Infectious Diseases 2011 11:335.

Submit your next manuscript to BioMed Central and take full advantage of:

- Convenient online submission

- Thorough peer review

- No space constraints or color figure charges

- Immediate publication on acceptance

- Inclusion in PubMed, CAS, Scopus and Google Scholar

- Research which is freely available for redistribution

Submit your manuscript at www.biomedcentral.com/submit 